\title{
Contribution to the Development of Simulation Model of Ship Turbine
}

\author{
Ratko Božić, Frane Mitrović, Sandro Božić \\ Split Ship Management \\ Boktuljin put bb \\ 21000 Split, Croatia
}

\begin{abstract}
Simulation modelling, performed by System Dynamics Modelling Approach and intensive use of computers, is one of the most convenient and most successful scientific methods of analysis of performance dynamics of nonlinear and very complex natural technical and organizational systems [1]. The purpose of this work is to demonstrate the successful application of system dynamics simulation modelling at analyzing performance dynamics of a complex system of ship's propulsion system. Gas turbine is a complex non-linear system, which needs to be systematically investigated as a unit consisting of a number of subsystems and elements, which are linked by causeeffect $(U P V)$ feedback loops $(K P D)$, both within the propulsion system and with the relevant surrounding. In this paper the authors will present an efficient application of scientific methods for the study of complex dynamic systems called qualitative and quantitative simulation System Dynamics Methodology. Gas turbine will be presented by a set of non-linear differential equations, after which mental-verbal structural models and flowcharts in System dynamics symbols will be produced, and the performance dynamics in load condition will be simulated in POWERSIM simulation language..
\end{abstract}

\section{Introduction}

Dynamic investigation of nonlinear engine (especially electric engine) systems is a relatively considerable problem in the area of investigating performance dynamics of ship's propulsion systems. Ship gas turbine, belongs, undoubtedly, to a set of linear complex technical systems, which consist of two main subsystems - turbine system and ship synchronous generator.

In this work ship three-phase self-excited synchronous generator has been treated as particular sensitive consumer which is driven by ship gas turbine, which means that they are the main source of alternating voltage of ship energy consumers.

\section{System dynamics modelling of twin shaft gas}

simulating

Most often dynamic analysis of gas turbine is based on observation of plan as accumulator of kinetic energy, while dynamics of thermal energy can be conditionally ignored.

We presume that the process of fuel combustion is temporary, condition of pressure in turbine is constant, engine air rate equals gas consumption, parameters of atmospheric pressure are relatively unchanged, and ideal heat transfers. Linear behaviour of plan is available when fuel consumption does not depend on angular velocity of turbo compressor rotor.

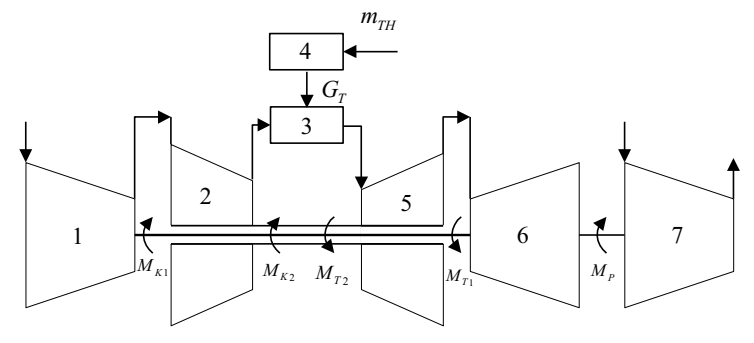

Figure 1. Standard scheme of the system of two shaft gas block turbine

1- low pressure compressor; 2 - high pressure compressor; 3 combustion chamber,4-fuel pump; 5- high pressure turbine; 6low pressure turbine; 7- consumers

Mathematical model of dynamic performance of gas turbine is presented like this [11]:

$$
\mathrm{T}_{1} \dot{\varphi}_{\omega}+\varphi_{\omega}=\mathrm{k}_{\mathrm{G}} \mu_{\mathrm{G}}-\mathrm{k}_{\mathrm{b}} \mu_{\mathrm{b}}-\mathrm{f}(\mathrm{t})
$$

where:

$\varphi_{\omega}$ - relative change of angular speed,

$\omega \quad$ - turbine angular speed,

$\Delta \omega$ - absolute change,

$\mu_{\mathrm{G}}$ - relative change of fuel consumption,

$\mathrm{G}_{\mathrm{t}} \quad$ - absolute fuel consumption

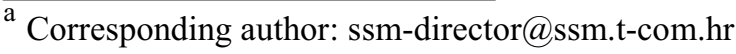


By developing the equation a final differential form in explicit form is reached:

Equations of shaft of turbo compressor with low pressure - consumer:

$$
\begin{gathered}
\mathrm{T}_{\mathrm{a} 1} \varphi_{\omega 1}+\mathrm{k}_{1} \varphi_{\omega 1}=\mu_{\mathrm{G}}+\mathrm{k}_{\omega 2} \varphi_{\omega 2} \\
\frac{\mathrm{d} \varphi_{\omega 1}}{\mathrm{dt}}=\frac{\mathrm{k}_{1}}{\mathrm{~T}_{\mathrm{a} 1}}\left[\frac{\mu_{\mathrm{G}}}{\mathrm{k}_{1}}+\frac{\mathrm{k}_{\omega 2} \varphi_{\omega 2}}{\mathrm{k}_{1}}-\frac{\mathrm{f}(\mathrm{t})}{\mathrm{k}_{1}}-\varphi_{\omega 1}\right] \\
\frac{\mathrm{d} \varphi_{\omega 1}}{\mathrm{dt}}=\frac{1}{\mathrm{~T}_{\mathrm{a} 1}}\left(\mu_{\mathrm{G}}+\mathrm{k}_{\omega 2} \varphi_{\omega 2}-\mathrm{f}(\mathrm{t})-\mathrm{k}_{1} \varphi_{\omega 1}\right)
\end{gathered}
$$

Equations of shaft of turbo compressor with high pressure:

$$
\begin{aligned}
& \mathrm{T}_{\mathrm{a} 2} \varphi_{\omega 2}+\mathrm{k}_{2} \varphi_{\omega 2}=\mu_{\mathrm{G}}+\mathrm{k}_{\omega 1} \varphi_{\omega 1} \\
& \frac{\mathrm{d} \varphi_{\omega 2}}{\mathrm{dt}}=\frac{\mathrm{k}_{2}}{\mathrm{~T}_{\mathrm{a} 2}}\left[\frac{\mu_{\mathrm{G}}}{\mathrm{k}_{2}}+\frac{\mathrm{k}_{\omega 1} \varphi_{\omega 1}}{\mathrm{k}_{2}}-\varphi_{\omega 2}\right] \\
& \frac{\mathrm{d} \varphi_{\omega 2}}{\mathrm{dt}}=\frac{1}{\mathrm{~T}_{\mathrm{a} 2}}\left(\mu_{\mathrm{G}}+\mathrm{k}_{\omega 1} \varphi_{\omega 1}-\varphi_{\omega 2}\right)
\end{aligned}
$$

The equations are:

Time of shaft 1. and 2. running (fig. 1.):

$$
T_{a 1}=\frac{I_{1} \omega_{1 n}}{\left(\frac{\partial M_{T 1}}{\partial G_{T}}\right)_{0} G_{T n}} ; \quad T_{a 2}=\frac{I_{2} \omega_{2 n}}{\left(\frac{\partial M_{T 2}}{\partial G_{T}}\right)_{0} G_{T n}}
$$
is:

Self regulating coefficient of shaft 1. (fig. 1.)

$$
k_{1}=\frac{\left[\left(\frac{\partial M_{K 1}}{\partial \omega_{1}}\right)_{0}-\left(\frac{\partial M_{T 1}}{\partial \omega_{1}}\right)_{0}\right] \omega_{1 n}}{\left(\frac{\partial M_{T 1}}{\partial G_{T}}\right)_{0} G_{T n}}
$$
is:

Self regulating coefficient of shaft 2. (fig. 1.)

$$
k_{2}=\frac{\left[\left(\frac{\partial M_{K 2}}{\partial \omega_{2}}\right)_{0}-\left(\frac{\partial M_{T 2}}{\partial \omega_{2}}\right)_{0}\right] \omega_{2 n}}{\left(\frac{\partial M_{T 2}}{\partial G_{T}}\right)_{0} G_{T n}}
$$

Coefficient of increasing of angular speed $\omega_{2}$ upon angular speed $\omega_{l}$

$$
k_{\omega 1}=\frac{\left[\left(\frac{\partial M_{T 2}}{\partial \omega_{1}}\right)_{0}-\left(\frac{\partial M_{K 2}}{\partial \omega_{1}}\right)_{0}\right] \omega_{1 n}}{\left(\frac{\partial M_{T 2}}{G_{T}}\right)_{0} G_{T n}}
$$

Coefficient of increasing of angular speed $\omega_{l}$ upon angular speed $\omega_{2}$

$$
k_{\omega 2}=\frac{\left[\left(\frac{\partial M_{T 1}}{\partial \omega_{2}}\right)_{0}-\left(\frac{\partial M_{K 1}}{\partial \omega_{2}}\right)_{0}\right] \omega_{2 n}}{\left(\frac{\partial M_{T 1}}{G_{T}}\right)_{0} G_{T n}}
$$

Relative variation of possible external act of cargo

$$
f(t)=\frac{\Delta M_{G}[f(t)]}{\left(\frac{\partial M_{T 1}}{\partial G_{T}}\right)_{0} G_{T n}}
$$

Relative variation of angular speed $\omega_{1}$ and $\omega_{2}$

$$
\varphi_{\omega 1}=\frac{\omega_{1}}{\omega_{1 n}} ; \quad \varphi_{\omega 2}=\frac{\omega_{2}}{\omega_{2 n}}
$$

Relative variation of fuel consumption

$$
\mu_{G}=\frac{\Delta G_{T}}{G_{T n}}
$$

where are:

$\omega_{1}$ - angular speed of first shaft $\left(\mathrm{s}^{-1}\right)$,

$\omega_{2}$ - angular speed of second shaft $\left(\mathrm{s}^{-1}\right)$,

$\omega_{1 n}-$ nominal angular speed of first shaft ( $\mathrm{s}$

$1)$,

$\omega_{2 n}$ - nominal angular speed of second shaft $\left(\mathrm{s}^{-1}\right)$,

$\Delta G_{T}$ - absolute variation of fuel consumption

$(\mathrm{t} / \mathrm{h})$,

$G_{T n}$ - nominal fuel consumption $(\mathrm{t} / \mathrm{h})$,

$I_{1} \quad$ - moment of inertia of rotating masses of first shaft $\left[\mathrm{kgm}^{2}\right]$

$I_{2} \quad$ - moment of inertia of rotating masses of second shaft $\left[\mathrm{kgm}^{2}\right]$

$M_{K_{1}}$ - torque of low-pressure compressor $(\mathrm{Nm})$

$M_{K 2}$ - torque of high-pressure compressor $(\mathrm{Nm})$

$M_{T 1}$ - torque of low-pressure turbine $(\mathrm{Nm})$

$M_{T 2}$ - torque of high-pressure turbine $(\mathrm{Nm})$

\subsection{System Dynamics qualitative model of twin shaft gas turbine}

Qualitative simulation models, or mental and verbal, structural model and flow diagram of ship gas turbine for the explicit differential equation (4) will be:

When relative variation of fuel consumption $\mu_{G}$ and product $k_{2} * \varphi_{\omega 2}$ are increasing, relative angular speed variation is also increasing, resulting in positive causeconsequence relation UPV $(+)$. When relative variation of possible external act of cargo and product $k_{1} * \varphi_{\omega l}$ are increasing, relative angular speed variation is decreasing and observed UPV(-) is negative. Further, when time of shaft running Ta1 is increasing, relative angular speed variation is decreasing, resulting in negative sign UPV(-). In accordance to the developed mental and verbal model, structural model and flow diagram in DYNAMO symbols [2] of the equation of the state (4) follow: 




Figure 2. Structural diagram of turbo compressor with low pressure

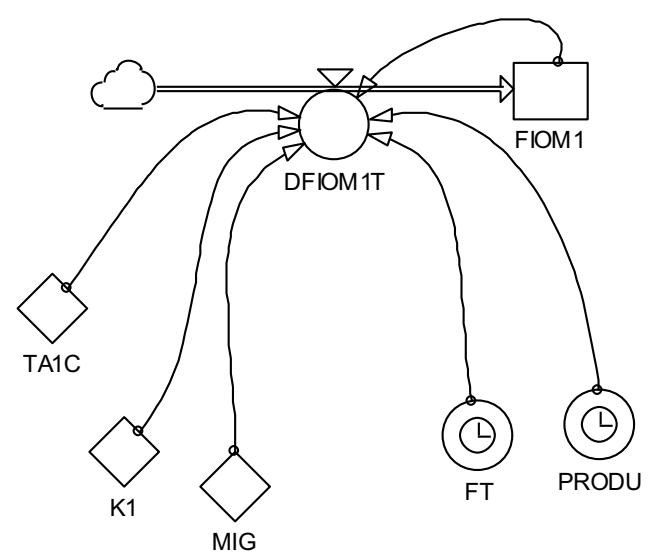

Figure 3. Flow diagram of turbo compressor with low pressure

Qualitative simulation models, or mental and verbal, structural model and flow diagram of ship gas turbine for the explicit differential equation (7) will be:

When relative variation of fuel consumption $\mu_{G}$ and product $k_{2} * \varphi_{\omega 2}$ are increasing, relative angular speed variation is also increasing, resulting in positive cause-consequence relation UPV $(+)$.Further, when time of shaft running $T_{a l}$ is increasing, relative angular speed variation is decreasing, resulting in negative sign UPV (-).

In accordance to the developed mental and verbal model, structural model and flow diagram follow, given in DYNAMO symbols [2] of the equation of the state (7):

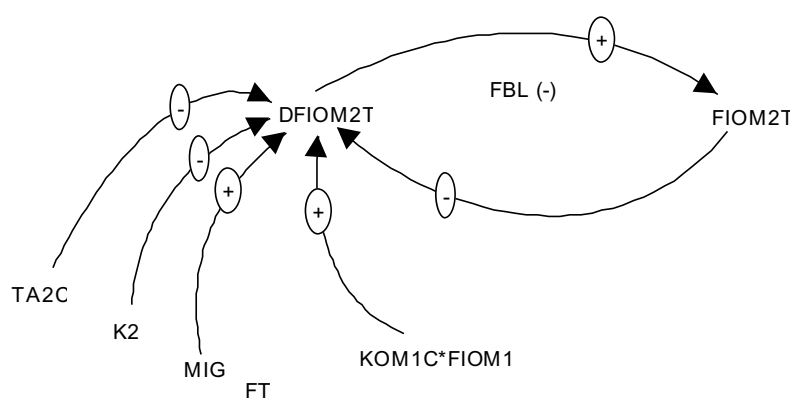

Figure 4. Structural diagram of turbo compressor with high pressure



Figure 5. Flow diagram of turbo compressor with high pressure

\section{Computing Simulating model of the gas-turbo generator}

Simulation scenario

Run of the turbine is triple-stage, which means that in TIME $=1$ second turbine is accelerated by bringing the fuel. At $10 \%$ of the nominal number of revolution in $\mathrm{TIME}=5$ seconds fuel consumption is increased to the $35 \%$ of nominal number of revolution, and in TIME $=10$ fuel supply is increased, and in that way "uniform" heating of turbine i.e. nominal number of revolution is obtained. In TIME=15 PID regulator is under the shock loading from gas turbine, in the amount of $50 \%$ of nominal load, meaning that $F(t)=0.5$. In $\mathrm{TIME}=30$ stochastic load occurs.

Graphics results of the simulation:



Figure 6. Relative angular speed variation, relative angular speed variation of second shaft, relative variation of fuel consumption

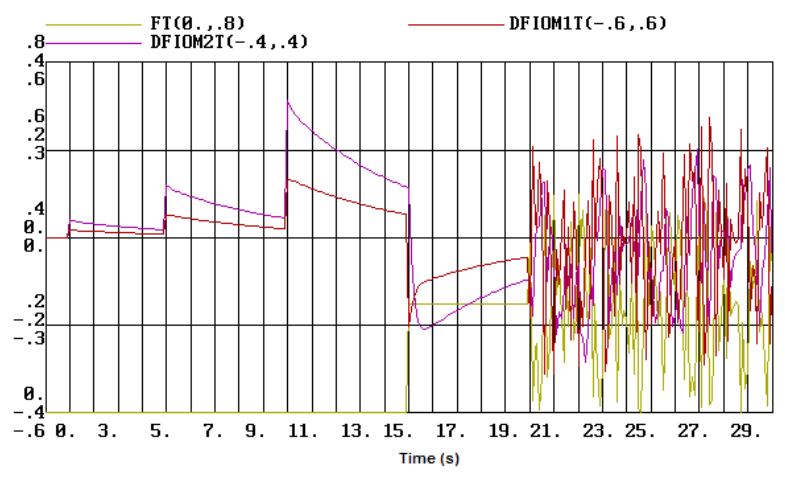

Figure 7. Speed variation of relative angular speed, speed variation of relative angular speed of second shaf 


\section{Conclusion}

The application of System Dynamics Simulation Modelling Approach of the complex marine dynamic processes revealed the following facts:

1. System Dynamics Modelling Approach is a very suitable software education tool for marine students and engineers.

2. System Dynamics Computer Simulation Models of marine systems or processes are very effective and successfully implemented in simulation and training courses as part of the marine education process.

\section{References}

1. W.J. Forrester, Principles of Systems, MIT Press, Cambridge Massachusetts, USA, (1973)

2. P. Richardson, George and L. Aleksander, Introduction to System Dymanics Modelling with Dynamo, MIT Press, Cambridge, Massachusetts, USA, (1981)

3. A. Munitic, Computer Simulation with Help of System Dynamics, Croatia, BIS Split, (1989)

4. A. Munitic,, L. Milic and M. Milikovic, System Dynamics Computer Simulation Model of the Marine Diesel-Drive Generation Set, Automatic Control System." IMACS World Congress on
Scientific Computation, Modelling and Applied Matematichs, vol.5, Wiessenschaft \& Technik Verlag, Berlin, (1997)

5. A. Munitic, Application Possibilities of System Dynamics Modelling, System Dynamics, Proceedings of the SCS Western Multiconference, San Diego, California, A Society for Computer Simulation International, San Diego, USA, (1989)

6. A. H. Byrknes, Run-Time User's Guide and Reference Manual, Powersim 2.5, Powersim Corporation, Powersim AS, 12007 Sunrise Valley Drive, Reston Virginia 22091 USA.

7. A. Munitic, I. Kuzmanic,, M. Krcum, System Dynamic Simulation Modelling of the Marine Synchronous Generator, Modelling and Simulation, IASTED, Pittsburgh, 372-375, (1998)

8. L.I. Isakov, L.I. Kutljin, Kompleksnaja avtomatizacija sudovljlh dizeljnih i gazoturbinmljih ustanovok, in Russian, Leningrad, Sudostreonnie, (1984)

9. G.F. Suprun, G.F.,Sintezsistem elektroenergetiki sudov, in Russian; Leningrad, Sudostroenie, (1972)

10. A.Hind, A., Automation in merchant ships, London, (1968)

11. R. A. Nalepin, O.P. Demeenko, Avtomatizacija sudovljih energetskih ustanovok, Sudostroennie, in Russian, (1975) 